\title{
DIREITOS DA PERSONALIDADE E TRANSEXUALIDADE: UMA (RE)LEITURA A PARTIR DO CORPO NA MODERNIDADE
}

\author{
RIGHTS OF PERSONALITY AND TRANSEXUALITY: A (RE) READING FROM THE BODY IN \\ MODERNITY
}

\section{Dirceu Pereira Siqueira}

Pós-doutor em Direito pela Faculdade de Direito da Universidade de Coimbra (Portugal) Doutor e Mestre em Direito Constitucional pela Instituição Toledo de Ensino - ITE/Bauru Coordenador e Professor Permanente do Programa de Doutorado e Mestrado em Direito do Centro Universitário Cesumar (UniCesumar) Professor nos cursos de graduação em direito da Universidade de Araraquara (UNIARA), do Centro Universitário Unifafibe (UNIFAFIBE) e do Centro Universitário da Fundação Educacional de Barretos (UNIFEB)

E-mail: dpsiqueira@uol.com.br

\section{Douglas Santos Mezacasa}

Mestre em Direito pelo Programa de Mestrado em Ciências Jurídicas da UniCesumar Especialista em Direito Previdenciário pela Universidade Estadual de Londrina (UEL) e Advogado.

E-mail: dmezacasa@gmail.com

\section{Vitor Hugo Marani}

Doutorando do Programa de Pós-Graduação Associado em Educação Física UEM-UEL e integrante do Grupo de Pesquisa Corpo, Cultura e Ludicidade DEF/UEM/CNPq

Professor da Universidade Federal de Mato Grosso - UFMT/CUA

E-mail: vitorhmarani@gmail.com

Recebido em: 07/03/2018

Aprovado em: 17/12/2018

RESUMO: O objetivo central do texto baseia-se na discussão da transgenitalização como efetivação do direito da personalidade a partir das dimensões da autoidentidade e do corpo na modernidade, por meio das contribuições do teórico inglês, Anthony Giddens. Para tanto, tratouse do tema, a partir de incursões teóricas que buscassem discutir as novas relações sociais e como esse processo auxilia na construção de novas identidades na modernidade, bem como o corpo, na teoria de Anthony Giddens, é pensado como elemento fundamental para a projeção da autoidentidade. Por fim, discutiu-se o processo de transgenitalização e alteração do nome civil como meio de adequação do corpo, a partir de dimensões jurídicas que amparam a legalidade do processo de mudança de sexo, no intuito de garantir a aplicabilidade do princípio constitucional da dignidade da pessoa humana.

Palavras-chave: Acesso à justiça; Direitos da Personalidade; Transexualidade; Inclusão Social: Gênero. 
ABSTRACT: The central objective of the text is based on the discussion of transgenitalization as an effective personality right from the dimensions of self-identity and the body in modernity through the contributions of the English theorist Anthony Giddens. In order to do so, the topic was based on theoretical incursions that sought to discuss the new social relations and how this process helps in the construction of new identities in modernity, and the body, in Anthony Giddens's theory, is thought as a fundamental element for the projection of self-identity. Finally, we discussed the process of transgendering and changing the civil name as a means of adapting the body, based on legal dimensions that support the legality of the sex-change process, in order to ensure the applicability of the constitutional principle of the dignity of the human person

Keywords: Access to Justice; Rights of Personality; Transexuality; Social Inclusion; Gender.

SUMÁRIO: Introdução; 1 A modernidade e os novos contornos atribuídos à autoidentidade; 2 A construção do corpo: projeções da autoidentidade; 3 A transgenitalização como efetivação do direito da personalidade na modernidade; Considerações finais; Referências.

\section{INTRODUÇÃO}

As transformações do ordenamento jurídico brasileiro, advindas da consolidação da Constituição da República Federativa de 1988, aliadas ao Código Civil de 2002, retratam a adoção de novas posturas legais no que diz respeito ao antropocentrismo do sistema legislativo, denominado como "repersonalização do direito privado"1. Decorre dessa "repersonalização", a introdução de um rol amplo de direitos humanos, constatado principalmente pela visualização do artigo $1^{\circ}$ da referida constituição que insere a dignidade da pessoa humana como um dos fundamentos do Estado, a partir do viés antropocêntrico, o que ampliou as possibilidades de compreensão das novas formas de constituição social da personalidade dos indivíduos ${ }^{2}$.

Dentre as novas demarcações sociais da personalidade, constam aquelas relacionadas às diferenças de gênero e de sexualidade, como é o caso dos transexuais. Embora seja notória a existência de um Estado Democrático de Direito, guiado pelo respeito e pela não distinção de qualquer natureza, a tutela por parte do Estado junto a esses indivíduos não é marcada por sua inserção social plena, especialmente em termos jurídicos, haja vista que existem apenas decisões jurisprudenciais espalhadas pelo país, e não legislações que, de fato, os amparem ${ }^{3}$. Daí a necessidade de investigações e propostas que almejem refletir sobre tais questões, amparadas no compromisso ético-moral da inclusão e da diversidade.

Por isso, a reflexão proposta neste texto perpassa questões ligadas à pessoa transexual, bem como ao meio de efetivação do direito da personalidade desses indivíduos, especificamente, por meio da transgenitalização. Para tanto, metodologicamente, a pesquisa possui caráter qualitativo, do tipo bibliográfico, a partir da construção teórica sociológica por meio das dimensões da autoidentidade e do corpo na modernidade junto às leituras das obras do teórico inglês Anthony Giddens (GIDDENS, 1991; 1993; 1994; 2002; 2005). O diálogo com tal autor deu-se por conta de seus escritos envolvendo as transformações da intimidade ${ }^{4}$, da compreensão do gênero e da

\footnotetext{
${ }^{1}$ SZANIAWSKI, E. Direitos de Personalidade e sua Tutela. 2. ed. São Paulo: Revista dos Tribunais, 2005.

${ }^{2}$ SZANIAWSKI, E. Limites e possibilidades do direito de redesignação do estado sexual: estudo sobre o transexualismo, aspectos médicos e jurídicos. São Paulo: Revista dos Tribunais, 1999.

${ }^{3}$ STURZA, J. M., SCHORR, J. S. Transexualidade e os direitos humanos: tutela jurídica ao direito à identidade. Revista Jurídica Cesumar Jan./Jun. 2015, v. 15, n. 1, p. 265-283.

${ }^{4}$ GIDDENS, Anthony. A transformação da intimidade: sexualidade amor e erotismo nas sociedades. São Paulo: Editora da Unesp, 1993.
} 
sexualidade a partir de um novo tempo social denominado por ele de modernidade reflexiva, marcada por papéis sociais destituídos da tradição e, cada vez mais, amparados em novos estilos de vida e narrativas biográficas.

Nesses novos cenários culturais decorrentes da modernidade, questões que envolvem a compreensão do que é ser homem e o que é ser mulher não estão associadas fundamentalmente com o sexo do corpo nato, o que implica em pensar em categorias que não são facilmente classificáveis e, por isso, interessa às esferas sociais e jurídicas, por exemplo. Tem-se o gênero e a sexualidade como constructos sociais ligados ao corpo humano, sujeitos às forças sociais que o moldam e, também, ao agenciamento no interior de diferentes contextos sociais. Surge desse pressuposto, a possibilidade dos indivíduos escolherem construir e reconstruir seus corpos como bem desejarem - por meio de exercícios, dietas, entre outras alterações, submetendo-se a cirurgias plásticas e operações de mudança de sexo ${ }^{5}$.

A partir das categorias eleitas para a discussão da transgenitalização como meio de efetivação do direito da personalidade via trato da autoidentidade e do corpo na modernidade, o texto organiza-se em três seções. A primeira, intitulada A modernidade e os novos contornos atribuídos à autoidentidade, visa pensar as novas relações sociais e como esse processo auxilia na construção de novas identidades na modernidade. A construção do corpo: projeções da autoidentidade, segunda seção do texto, retrata como o corpo, na teoria de Anthony Giddens, é pensado como elemento fundamental para a projeção da autoidentidade. E, por fim, $A$ transgenitalização como efetivação do direito da personalidade na modernidade, almeja discutir o processo de transgenitalizaçãoe alteração do nome civil a partir de dimensões jurídicas que amparam a legalidade do processo de mudança de sexo, como reflexo das mudanças sociais instauradas na modernidade.

\section{A MODERNIDADE E OS NOVOS CONTORNOS ATRIBUÍDOS À AUTOIDENTIDADE}

A modernidade refere-se às instituições e modos de comportamento estabelecidos pela primeira vez na Europa, depois do feudalismo, mas que no século XX tornaram-se mundiais em termos de impacto. Dentre as dimensões que integram a modernidade, o sociólogo aponta a relação com a industrialização, com o sistema de produção de mercadorias e mercantilização da força de trabalho, com as instituições de vigilância e de controle dos meios de violência também são assinalados como dimensões da modernidade. Da modernidade, houve a criação do estado-nação que contrasta com as organizações tradicionais anteriores e que, atualmente, encontra-se numa relação global, repletas de organização burocrática, no sentido de "controle regular das relações sociais dentro de distâncias espaciais e temporais indeterminadas" 6 .

Para explicar as transformações na modernidade que direcionam as experiências tradicionais rumo às pós-tradicionais, Anthony Giddens elege três elementos que elucidam essa transição. O primeiro é o rompimento com as velhas formas de "comunidade", demarcado no fim do século XIX e com aspectos conservadores, o que desencadeou a "desinstitucionalização" da vida privada e "demasiada institucionalização" da vida pública. O segundo recai na maneira como as instituições modernas assumem as áreas da vida social, despojando-as do conteúdo significativos inerentes a ela em sua essência. E, o terceiro elemento pensado pelo autor, está ligado às práticas sociais cotidianas, relacionadas ao lugar, ao parentesco, à amizade e às relações sexuais que, em situações modernas, tornam-se ativamente ressurgentes ${ }^{7}$.

Tais características difundem-se e contribuem para o alargamento das experiências humanas que se instituem a partir de novas dinâmicas sociais, produzidas em meio a uma série de

${ }^{5}$ GIDDENS, A. Sociologia. Porto Alegre: Artmed, 2005.

${ }^{6}$ GIDDENS, A. Modernidade e identidade. Rio de Janeiro: Zahar, 2002, p. 22

${ }^{7}$ GIDDENS, A. As consequências da modernidade. São Paulo: Editora da Universidade Estadual Paulista, 1991.

Revista de Direito Brasileira | Florianópolis, SC | v. 22 | n. 9 | p.77-89 |Jan./Abr. 2019 
transformações que afeta a vida social cotidiana, devido ao dinamismo e interferência nos hábitos e costumes tradicionais, o que sugere novos projetos sociais, novas oportunidades de intimidade e de autoexpressão ${ }^{8}$. Surge desse panorama, o anúncio de uma época de finalizações que retrata a noção de "ruptura" com a tradição.

A partir desses elementos, sentimentos de desorientação, de mal-estar e de evidente transição no mundo como um todo passam a fazer parte do cotidiano das pessoas. Tais observações, sob o "disfarce" da emergência de uma sociedade pós-tradicional, sugere pensar uma oposição à tradição, não como dissolução dessa dimensão, mas como reconstrução contínua, que ocorre em 'movimento'. Por isso, nota-se experiências do cotidiano que ainda refletem o papel da tradição no contexto do deslocamento e da (re)apropriação do conhecimento 9 .

Sobre a tradição, o sociólogo inglês explica que ela "está ligada ao ritual e tem suas conexões com a solidariedade social, mas não é a continuidade mecânica de preceitos que é aceita de modo inquestionável". Para ele, é a cola que liga as ordens sociais pré-modernas, como orientação ao passado, de tal forma que o passado tem uma pesada influência sobre o presente e, também, sobre o futuro. É importante tencionar que na ordem pós-tradicional, não há desaparecimento total das tradições, pelo contrário, há casos em que elas florescem por meio do processo discursivo, justificadas como tendo valor em um universo de valores competitivos plurais ${ }^{10}$.

Diferentemente da sociedade tradicional, a sociedade pós-tradicional estrutura-se em uma multiplicidade de sistemas abstratos, sendo a confiança uma parte necessária da vida cotidiana da atualidade. O mais importante é que a confiança nos sistemas abstratos está ligada a padrões de estilo de vida coletivos que, comumente, estão sujeitos à mudança. E, as escolhas de diferentes estilos de vida, nas sociedades modernas, são ao mesmo tempo constitutivas da vida cotidiana e ligadas a sistemas abstratos, o que atenta para o fato de que, alterações nas práticas de estilo de vida podem se tornar profundamente subversivas dos sistemas abstratos centrais ${ }^{11}$.

Logo, a rotinização na sociedade pós-tradicional torna-se vazia e, por isso, pode ser convertida em vício, decorrente de novos estilos de vidas escolhidos pelos indivíduos na condição de protagonistas de suas vidas. Nos contextos pós-tradicionais, "não temos outra escolha senão decidir como ser e como agir". Nessa esteira de pensamento, até os vícios são escolhas, uma vez que estão postos como maneiras de se enfrentar a multiplicidade de possibilidades ofertadas nos aspectos da vida cotidiana - a lógica está na produção de autonomia dada ao indivíduo localizado na sociedade pós-tradicional ${ }^{12}$.

Dada a complexidade da sociedade da modernidade reflexiva, há o abandono da imagem da "jaula de ferro", de Max Weber, entre outras imagens que tentem captá-la seguindo tais orientações, pois, para ele, o mundo da modernidade é muito mais aberto, fruto do conhecimento acumulado sobre o próprio humano e o ambiente. Esse conhecimento produz oportunidade e, ao mesmo tempo, riscos - elementos causados por conta da noção de natureza invadida pela socialização - o que atribui a dissolução da tradição e criação de outras possibilidades espaçotemporais fadadas à penetração das instituições modernas nos acontecimentos da vida cotidiana ${ }^{13}$.

A fase da 'modernização reflexiva' é marcada pelos processos concomitantes da globalização e da busca de contextos de ações tradicionais que, segundo o sociólogo inglês, altera o equilíbrio entre tradição e modernidade. Como explica, a globalização é uma questão do "aqui", que afeta até os aspectos mais íntimos da vida, em contrapartida, a tradição diz respeito à

${ }^{8}$ GIDDENS, op. cit., 2002.

${ }^{9}$ GIDDENS, A. A vida em uma sociedade pós-tradicional. In: BECK, U.;GIDDENS, A.; LASH, S. Modernização reflexiva: política, tradição e estética na ordem social moderna. 1994.

${ }^{10}$ GIDDENS, op. cit., 1994.

${ }^{11}$ GIDDENS, op. cit., 1994.

${ }^{12}$ GIDDENS, op. cit., 1994.

${ }^{13}$ GIDDENS, op. cit., 1994.

Revista de Direito Brasileira | Florianópolis, SC | v. 22 | n. 9 | p. 77-89 |Jan./Abr. 2019 
organização e ao controle do espaço mediante o controle de tempo. A globalização é, essencialmente a "ação à distância", ou seja, a ausência predomina sobre a presença, não na sedimentação do tempo, mas graças à reestruturação do espaço, o que promove nova dinâmica social.

As relações dialéticas entre local e global, que culminam na globalização e na transformação da autoidentidade acabam por gerar novas formas de mediação junto às experiências sociais. Tais mediações acabam sendo reformuladas na modernidade por conta do uso das tecnologias e da mídia que alteram a noção de linguagem e de socialização e auxiliam nas transformações espaço-temporais, culminando nas experiências transmitidas pela mídia na modernidade. Essas experiências ocorrem por meio do "efeito colagem" e da "intrusão de eventos distantes na consciência cotidiana" e auxiliam na formação da realidade e não um espelhamento dela.

Somado a esses aspectos, os riscos presentes na alta modernidade - e as implicações dos riscos para a confiança no conhecimento técnico dos sistemas abstratos - contribuem para a visualização de novas formas sociais que entrelaçam o local ao global. Decorre desse processo a inter-relação entre indivíduo e sociedade num aspecto global, como jamais visto na história da humanidade. Tem-se, o projeto reflexivo do "eu", que não se dá em meio a biografias estáticas e já consolidadas, como ocorria nas sociedades pré-modernas: a identidade é construída à medida que é encarada, com base nos sistemas abstratos e nos riscos a serem calculados ${ }^{14}$.

Tais alterações, como argumenta o autor, não emergem apenas no âmbito das relações macro, mas estão intimamente ligadas ao "eu", à vida individual e, por isso, a visualização da modernidade como algo que revela a crescente interconexão entre o global e o local. A autoidentidade, nessa perspectiva, consolida-se como trajetória a ser escolhida em meio a diferentes situações institucionais, o que desemboca na experiência local-global de uma "biografia reflexivamente organizada em termos do fluxo de informações sociais e psicológicas sobre possíveis modos de vida"15. Daí a necessidade de discussão da construção da autoidentidade para se compreender os mecanismos de projeção do corpo na modernidade reflexiva.

\section{A CONSTRUÇÃO DO CORPO: PROJEÇÕES DA AUTOIDENTIDADE}

A construção do eu, assim como em outros contextos mais amplos, ocorre a partir do processo de reflexividade, uma vez que essa tarefa é "realizada em meio a uma enigmática diversidade de opções e possibilidades" vislumbradas na modernidade. Nessa modernidade, a estrutura reflexiva do self visa manter narrativas biográficas coerentes, embora continuamente revisadas, baseadas em múltiplas escolhas filtradas por sistemas abstratos que assinalam novos estilos de vida emergentes, dentre os quais, no âmbito das relações de gênero e sexualidade, a transexualidade insere-se como nova possibilidade ${ }^{16}$. O projeto reflexivo do "eu", que não se dá em meio a biografias estáticas e já consolidadas, como ocorria nas sociedades pré-modernas é construída à medida que é encarada.

Do panorama moderno, o sociólogo apresenta alguns elementos para a compreensão da autoidentidade na modernidade, a saber: a) a construção do eu depende do indivíduo e, por isso, é reflexivo; b) a trajetória do eu parte de um passado em direção a um futuro antecipado; c) a reflexividade do eu é contínua; d) a autoidentidade pressupõe a construção de narrativas coerentes; e) o corpo é tomado como sistema de ação da autoidentidade reflexiva; f) a autorealização é tomada pelo equilíbrio entre oportunidade e risco e, seu tecido moral é a autenticidade; g) o curso da vida

\footnotetext{
${ }^{14}$ GIDDENS, op. cit., 2002.

${ }^{15}$ GIDDENS, op. cit., 2002.p. 20.

${ }^{16}$ GIDDENS, op. cit., 2002.
}

Revista de Direito Brasileira | Florianópolis, SC | v. 22 | n. 9 | p.77-89 |Jan./Abr. 2019 
é visto como série de passagens; h) a linha de desenvolvimento do eu é referida, pois parte da maneira como o indivíduo constrói e reconstrói sua história de vida.

$\mathrm{O}$ eu, posto como fruto da reflexividade, em parceria com a influência dos sistemas abstratos, afeta de modo difuso corpo e os processos psíquicos, que passam a ser mobilizados na modernidade. $\mathrm{O}$ autor afirma que, por mais que pareça uma tendência narcisista de cuidado à aparência corporal, há "uma preocupação muito mais profunda com a "construção" e o controle ativo do corpo"17. Estabelece-se, nessa direção, a conexão entre desenvolvimento corporal e estilo de vida - a exemplo de regimes corporais específicos e da reprodução genética e intervenção médica. O corpo, como sugere, está se tornando uma questão de escolhas e opções que não afetam apenas o indivíduo, mas estão intimamente ligadas às questões globais.

Os contornos da autoidentidade estão demarcados pelo corpo e possibilitam aos indivíduos o aprendizado para que sejam agentes competentes. Essa competência é a capacidade de exercer um monitoramento contínuo e bem-sucedido da face e do corpo - sua gestualidade e suas expressões em meio às interações sociais - que evidenciam o quanto não há nada de errado na vida cotidiana. Daí o controle rotineiro do corpo ser crucial para a manutenção do casulo protetor em situações de interação cotidiana, do contrário, sinaliza a tensão advinda da ameaça do referencial da segurança ontológica ${ }^{18}$.

A partir das mudanças da modernidade, tem-se o eu que se constrói reflexivamente e caracteriza-se por escolhas diárias. Tais escolhas delimitam estilos de vida, que demarcam a variedade de escolhas a serem selecionadas para a construção de uma narrativa biográfica reflexiva. Os estilos de vida são definidos como "conjunto mais ou menos integrado de práticas que um indivíduo abraça, não só porque essas práticas preenchem necessidades utilitárias, mas porque dão forma material a uma narrativa particular de autoidentidade" ${ }^{19}$. Com sugere o inglês, tais estilos de vida são adotados e não outorgados, como vistos em outros períodos pré-modernos. Simplesmente, estão abertos, de maneira reflexiva, à mudança à luz da natureza mutável da autoidentidade ${ }^{20}$.

Tem-se a "pluralização de mundos da vida", o que representa a descentralização de estilos de vida ligados estritamente a ambientes específicos de ação, abrindo espaços para ambientes de vida social moderno mais diverso e segmentado. Tais escolhas operam por meio da inquietação perante a dúvida presente na modernidade, e não pela crença nas certezas produzidas pelo conhecimento moderno. Ainda, outro fator importante a ser tratado diz respeito à prevalência da experiência transmitida pela mídia, como elemento influenciador da pluralidade de escolha do indivíduo moderno, seja a partir de maneiras óbvias, seja por maneiras sutis ${ }^{21}$.

O planejamento estratégico da vida assume papel importante diante de tantas alternativas de estilos de vida e reitera a trajetória construída reflexivamente pelo indivíduo moderno, o que permite a preparação de "ações futuras mobilizadas em termos da biografia do eu" 22. Esse planejamento, para além de integrar a vida cotidiana, também faz parte das instituições que regem a alta modernidade, por isso, sua assinatura estar presente, em maior ou menor grau, em diferentes circunstâncias e situações sociais de grupos particulares.

Essa pluralidade de escolhas também afeta as relações de intimidade humana e se aplicam à esfera corporal, uma vez que na alta modernidade, o corpo torna-se "cada vez mais socializado e integrado à organização reflexiva da vida social" 23 . Por isso a visualização do corpo (aparência e postura) como expressão importante da/na modernidade - que se difere dos modelos padronizados

${ }^{17}$ GIDDENS, op. cit., 2002.p. 15.

${ }^{18}$ GIDDENS, op. cit., 2002.

${ }^{19}$ GIDDENS, op. cit., 2002.p. 79.

${ }^{20}$ GIDDENS, op. cit., 2002.

${ }^{21}$ GIDDENS, op. cit., 2002.

${ }^{22}$ GIDDENS, op. cit., 2002.p. 83.

${ }^{23}$ GIDDENS, op. cit., 2002.p. 95. 
das culturas tradicionais que demarcavam muito mais a identidade social, do que a identidade pessoal. A aparência, nessa direção, aparece como elemento balizador do projeto reflexivo dos indivíduos.

Nesse panorama, o corpo participa de maneira direta de processos que não o consideram definitivo, gerando novas maneiras de cultivo e criação, principalmente a partir de padrões de sensualidade e de regimes corporais - temas tratados na obra. Tais constatações sugerem que a construção da autoidentidade ocorre, em tempos modernos, via processos internos que são frutos da reflexão do indivíduo e não dos elementos exteriores a eles, embora o mundo social também contribua para essa construção, uma vez que "o eu estabelece uma trajetória que só pode tornar-se coerente pelo uso reflexivo do ambiente social mais amplo"24.

A reflexividade do corpo e das ações corporais está na busca por atividades criadoras que reforcem o anseio pela autonomia, completamente relacionada com as relações sociais globais disponíveis na atualidade. Nota-se, desse panorama, a oferta diversificada de práticas corporais e procedimentos voltados ao corpo, o que produz novos conhecimentos em relação à postura dos indivíduos em relação às escolhas dos estilos de vida e nos tratamentos voltados ao corpo na alta modernidade. Daí a importância do projeto reflexivo do eu como elemento fundamental para se pensar a vida cotidiana na modernidade reflexiva.

$\mathrm{Na}$ modernidade reflexiva, o corpo ultrapassa seus limites biológicos, como um aspecto da natureza, governado de maneira fundamental por processos apenas marginalmente sujeitos à intervenção do ser humano. Com a invasão do corpo pelos sistemas abstratos, essa noção altera-se com mais intensidade, o que faz com que se torne "o lugar da interação, apropriação e reapropriação, ligando processos reflexivamente organizados ao conhecimento especializado sistematicamente ordenado" 25 .

A aparência e a projeção corporal servem como pontos focais para a reflexividade e, por isso, o corpo, como parte visível da autoidentidade, é capaz de apresentar a própria personalidade, construída reflexivamente em meio à possibilidade de estilos de vida disponibilizados socialmente. Como tal, o agenciamento reflexivo do próprio corpo torna-se uma condição necessária de "segurança ontológica", a coerência da autoidentidade e da competência no campo social. Por meio desse agenciamento, junto à ênfase de estilo, da aparência e de preferências sexuais, o corpo é transformado em uma projeção atraente no campo das relações interpessoais ${ }^{26}$.

Tem-se, na modernidade reflexiva, diversos recursos que contribuem para essa reflexividade direcionada ao corpo, a exemplo dos regimes corporais, dos tipos de exercícios, dos procedimentos estéticos, das cirurgias plásticas, entre outros que surgem com a ideia de agenciamento reflexivo do corpo. Tais possibilidades emergem do esforço para proteger o eu da marginalização social e do esquecimento total, bem como para garantir a popularidade e a estabilidade nas relações interpessoais, uma vez que os indivíduos participam ativamente do processo de criação reflexiva de sua própria imagem corporal ${ }^{27}$.

\section{A TRANSGENITALIZAÇÃO COMO EFETIVAÇÃO DO DIREITO DA PERSONALIDADE NA MODERNIDADE}

Conforme já destacado, a reflexividade que Anthony Giddens apresenta é produto e processo de novos estilos e padrões narrativos de vida que emergem na sociedade pós-tradicional. A partir de novas problemáticas impostas à sociedade, novas discussões ganham corpo em diferentes áreas do conhecimento, dentre as quais é possível destacar o Direito. Nessa direção, as

\footnotetext{
${ }^{24}$ GIDDENS, op. cit., 2002.p. 139.

${ }^{25}$ GIDDENS, op. cit., 2002.p. 200.

${ }^{26}$ GIDDENS, op. cit., 2002.

${ }^{27}$ GIDDENS, op. cit., 2002.
} 
garantias fundamentais do ser humano são discutidas e postas à análise diante de teorias que almejam resguardar a dignidade humana, abarcando os novos estilos de vida presentes na modernidade observada pelo sociólogo inglês. Por isso, a ideia neste tópico é de centralizar esforços para se compreender a condição do transexual no campo jurídico, assumindo a premissa de que o Direito, como área investigativa e de intervenção, vem para assegurar essas novas identidades que surgiram proporcionando meios que efetivem essas garantias individuais dos seres humanos.

Nesse sentido, para regular os direitos dos transexuais e daqueles que estão dispostos à readequação do corpo com a mente, é necessário entender o conceito do "ser transexual". Odon Maranhão ${ }^{28}$ define o transexual sendo uma pessoa cujo fenótipo é pertencente ao sexo definido, mas psicologicamente pertence ao sexo oposto, se comportando segundo este e rejeitando aquele. Para os autores Hogemann e Carvalho ${ }^{29}$, o transtorno de identidade de gênero é um transtorno de ordem psicológica e médica, sendo uma condição em que a pessoa nasce com o sexo biológico de um gênero, mas se identifica com os indivíduos pertencentes ao outro gênero, desejando viver e ser aceito enquanto pessoa do sexo oposto. Geralmente, é acompanhado de um sentimento de malestar ou de inadaptação ao seu sexo anatômico, manifestando desejo de submeter-se a uma intervenção cirúrgica e a tratamento hormonal, com o intuito de adequar seu corpo ao sexo almejado.

Ainda, Maria Helena Diniz ${ }^{30}$ refere-se à característica da transexualidade como uma condição sexual do ser humano que rejeita a sua própria identidade genética e, identifica psicologicamente com o gênero oposto. Trata-se de um drama jurídico-existencial por haver uma cisão entre a identidade sexual física e psíquica. Completa dizendo que o transexual é portador de desvio psicológico permanente de identidade sexual com rejeição do fenótipo e tendência à automutilação ou auto-extermínio, sentindo que nasceu com o corpo errado". A luz da medicina, a transexualidade, ainda é considerada uma patologia (CID-10F 64.0) tratada como um transtorno de identidade de viver e ser aceito pelo sexo oposto pertencente ao Grupo de Transtornos da Personalidade e do Comportamento Adulto. De acordo com Roberto Farina ${ }^{31}$ o indivíduo transexual nega seu sexo biológico e, exige a operação de reajustamento do corpo a fim de poder assumir a autoidentidade do verdadeiro gênero, que não condiz com seu sexo anatômico.

Assim, antes de adentrar na seara civil, onde o direito regula a redesignação de sexo em consonância com a alteração no nome do indivíduo, é necessário ressaltar o meio pelo qual se efetivará essa alteração sexual. A priori, o processo de transgenitalização está amparado pela Constituição Federal de 1988 ao inserir a saúde como um dos direitos sociais, como prevê o artigo 60: "São direitos sociais a educação, a saúde, a alimentação, o trabalho, a moradia, o transporte, o lazer, a segurança, a previdência social, a proteção à maternidade e à infância, a assistência aos desamparados, na forma desta Constituição" 32 .Tereza Rodrigues Vieira ${ }^{33}$ ressalta que o direito na obtenção da cirurgia de redesignação sexual se inclui no direito social à saúde, em sua acepção positiva, pois, o direito às medidas e prestações estaduais visa à prevenção das doenças e seus tratamentos.

\footnotetext{
${ }^{28}$ MARANHÃO, Odon. Curso de Medicina Legal. 4. ed.São Paulo: Revista dos Tribunais, 1989, p 193.

${ }^{29}$ CARVALHO, Marcelle Saraiva de; HOGEMANN, Edna Raquel. $O$ biodireito de mudar: transexualismo e o direito ao verdadeiro eu. Portal de e-governo, inclusão digital e sociedade do conhecimento. Maio, 2012.

${ }^{30}$ DINIZ, Maria Helena. O Estado Atual do Biodireito. $6^{\mathrm{a}}$ ed. Revisada, aumentada e atualizada. São Paulo: Saraiva, 2009. P. 280-281.

${ }^{31}$ FARINA, Roberto. Transexualismo: do homem à mulher normal através dos estados de intersexualidade e das parafilias. São Paulo: Novalunar, 1982, p. 117.

${ }^{32}$ BRASIL. Constituição da República Federativa do Brasil. Diário Oficial [da] União, Brasília, 5 out. 1988. Disponível em: <http://www.planalto.gov.br/ccivil_03/constituicao/constituicao.htm>. Acesso em: 27.set.2017.

${ }^{33}$ VIEIRA, Tereza Rodrigues. Nome e Sexo - Mudanças no Registro Civil. $1^{\text {a }}$ Edição. São Paulo: Editora Revista dos Tribunais, 2008. p. 221 e 229.
} 
Nesse contexto, o desejo de submeter-se a intervenções cirúrgicas e ao tratamento hormonal que visa a alteração do estereótipo do corpo para adequar ao sexo que se identifica, preocupou o Governo Federal Brasileiro na medida em que passou a adotar medidas que garantissem o acesso à essa população específica e protegessem a saúde, auxiliando no processo de transformação corporal por meio da Política Nacional de Saúde Integral de Lésbicas, Gays, Bissexuais Travestis e Transexuais, elaborado pelo Ministério da Saúde no ano de 2013 (Resolução $n^{\circ}$ 2, de 6 de Dezembro de 2011) ${ }^{34}$. A referida Resolução trata do Plano Operativo da população LGBT auxiliando no processo de enfrentamento das iniquidades e desigualdades em saúde sofrida pelos indivíduos, garantido o acesso à população LGBT e atenção integral á saúde.

Esta resolução e as demais legislações pertinentes se materializam como importantes instrumentos de efetivação dos direitos da personalidade, pois, ao serem implantadas de maneira correta e eficaz, possibilitam a adequação do corpo com a identidade de gênero do ser humano, estendendo ao Estado a garantia da proteção e o respeito pela vida e dignidade do indivíduo. Ademais, essa política está amparada pelos princípios gerais da Constituição Federal de 1988 (Princípio da Cidadania e proteção da Dignidade da Pessoa Humana - Artigo 5º incisos II e III da CF/1988). Ingo Wolfgang Sarlet estabelece que:

Onde não houver respeito pela vida e pela integridade física e moral do ser humano, onde as condições mínimas para uma existência digna não forem asseguradas, onde não houver limitação do poder, em fim, onde a liberdade e a autonomia, a igualdade (em direitos e obrigações) e os direitos fundamentais não forem reconhecidos e minimamente assegurados, não haverá espaço para a dignidade da pessoa humana e esta (a pessoa), por sua vez, poderá não passar de mero objeto de arbítrio e injustiças. ${ }^{35}$

Dessa forma, o desenvolvimento social passa a ser considerado imprescindível para a conquista da saúde dos transexuais e, a busca pela transgenitalização é a forma na qual o transexual se afirma como indivíduo na sociedade, materializando a efetivação de sua dignidade humana. Contudo, a cirurgia de redesignação de sexo e o tratamento hormonal, por si só, não garantem a transformação plena, fazendo-se necessários outros fatores que auxiliem e contribuem para essa associação de corpo e a autoidentidade na "construção" desse novo indivíduo ${ }^{36}$.

Para a concretização da nova autoidentidade, também é necessário que o direito auxilie e garanta um acesso pleno e efetivo de um dos direitos da personalidade humana: o nome civil. Ao falar de corpo, deve-se atentar, não apenas ao seu aspecto biológico, pois, seu aspecto cultural é determinante para que compreendam as imposições feitas a partir dos discursos que o normatizam (médico e jurídico) ${ }^{37}$. A alteração do nome civil do transexual o adequará a sua realidade fática com a realidade jurídica. Com a mudança do gênero, o nome do indivíduo passa a não mais corresponder à sua pessoa, tornando obsoleto seu registro civil, bem como todos os documentos

\footnotetext{
${ }^{34}$ RESOLUÇÃO no 2 de 6 de dezembro de 2011. Estabelece estratégias e ações que orientam o Plano Operativo da Política Nacional de Saúde Integral de Lésbicas, Gays, Bissexuais, Travestis e Transexuais, no âmbito do Sistema Único de Saúde (SUS). Disponível em:<http://bvsms.saude.gov.br/bvs/saudelegis/cit/2011/res0002_06_12_2011.html>. Acesso em: 26.set.2017.

${ }^{35}$ SARLET, Ingo Wolfgang. Dignidade da pessoa humana e direitos fundamentais na Constituição Federal de 1988. Porto Alegre: Livraria do Advogado, 2001.

${ }^{36}$ FERNANDES, Eric Baracho Dore.Os direitos da personalidade e a problemática dos transexuais. Revista de direito dos monitores da UFF. v.07. Jan/2010.

${ }^{37}$ OLIVEIRA, Ana Carolina Gondim de A.; VIANA, Alba Jean Batista; SOUSA, Eduardo Sérgio S. O Corpo intersexual como desconstrução dos gêneros inteligíveis: uma abordagem sócio-jurídica. In: Anais...17 Encontro Nacional da Rede Feminista Norte e Nordeste de Estudos e Pesquisa sobre a Mulher e Relações de Gênero. Disponível em: http://www.ufpb.br/evento/lti/ocs/index.php/17redor/17redor/paper/view/87>.
}

Revista de Direito Brasileira | Florianópolis, SC | v. 22 | n. 9 | p.77-89 |Jan./Abr. 2019 
que o usaram como base ${ }^{38 .}$ A autora Tereza Rodrigues Vieira refere-se ao nome civil como um mínimo essencial de sobrevivência ao transexual, in verbs:

O transexual não quer muito, quer apenas o mínimo essencial para uma sobrevivência digna, procurando o equilíbrio entre os direitos fundamentais e os sociais. O direito à busca do equilíbrio corpo-mente do transexual, ou seja, à adequação do sexo e prenome, está ancorado no direito ao próprio corpo, no direito à saúde e, principalmente, no direito à identidade sexual, a qual integra um poderoso aspecto da identidade pessoal ${ }^{39}$

Assim, o nome deve refletir o âmago da personalidade individual, condizer com seu estado pessoal e social, bem como deve estar consorte com o seu psiquismo, sua honra, imagem pessoal e social, não podendo ser ridículo ou vexatório ${ }^{40}$. A alteração do nome proporciona a sintonia do corpo e mente.

Para tanto, quando se trata dessa alteração, tem-se que destacar que o artigo 16 do Código Civil Brasileiro ${ }^{41}$ garante o direito ao nome e, nele está compreendido o nome e o prenome, sendo ele um direito fundamental imutável. Já a Lei de Registros Públicos (Lei n ${ }^{\circ}$ 6.015/1973) ${ }^{42}$ disciplina algumas hipóteses de cabimento de alteração do nome do registro civil, tais como o nome que exponha o seu portador ao ridículo ( $§$ único do art. 55), por interesse particular do indivíduo em até um ano após atingir a sua maioridade civil (art. 56); por motivo de coação ou ameaça decorrente de colaboração com a apuração de crime ( $\$ 7^{\circ}$ do art. 57); razões familiares (art. 57, $\S 2^{\circ}$ e $8^{\circ}$ ); por adoção de apelidos públicos notórios (art.58) e, por fim, para corrigir erro de digitação (art.110). Contudo, a referida lei não faz menção à troca de nomes após a redesignação sexual, cabendo ao poder judiciário realizar uma análise interpretativa e sistemática da lei para que, possibilite essa adequação pelas vias legais.

O distanciamento do nome civil com o corpo pode gerar uma série de constrangimentos que ferem a dignidade humana do transexual e, por isso, destaca-se a necessidade de novas formulações jurídicas que auxiliem esse processo ${ }^{43}$. Portanto, é a partir de uma análise interpretativa e sistemática do artigo 55, § único da Lei 6.015/1973 ("os oficiais do registro civil não registrarão prenomes suscetíveis de expor ao ridículo os seus portadores..."44) que a jurisprudência vem autorizando a adequação do nome ao corpo do indivíduo, ou seja, sempre que o nome o expor o indivíduo em situações vexatórias, poderá o indivíduo, pleitear, judicialmente, a sua mudança e adequação. Destaca-se decisão recente da Corte Interamericana de Direitos Humanos, que após publicar a Opinião Consultiva de 24 de Novembro de 2017, solicitada pela Costa Rica, emitiu parecer preceituando os países à realizar a alteração do nome sem a necessidade de ingressar na via judicial, podendo os próprios Cartórios de Registro Civil realizarem a troca.

Assim, Tereza Rodrigues Vieira reforça que, após a harmonização do corpo com o sexo psicológico e o nome civil, o indivíduo estará completo, no que diz respeito a sua sexualidade, pois, entendendo que a adequação do nome para o transexual é mais funcional e em nada prejudica terceiros, pois se trata de um direito da personalidade. ${ }^{45}$ Garantir o exercício pleno da

${ }^{38}$ FERREIRA, Patrícia Fortes Attademo; JARDIM, Lucas Cardoso. A cirurgia de transgenitalização e seus reflexos no direito. Revista Jurídica Cesumar. jul./dez. 2015, v. 15, n. 2, p. 565-580.

${ }^{39}$ VIEIRA, Tereza Rodrigues. Mudança de sexo: aspectos médicos, psicológicos e jurídicos. São Paulo: Santos,1996. ${ }^{40}$ VIEIRA, op. cit., 2008.

${ }^{41}$ BRASIL. Lei 10.406 de 10 de Janeiro de 2002. Institui o Código Civil. Diária Oficial [da] União. Disponível em: <http://www.planalto.gov.br/ccivil_03/leis/2002/L10406.htm>. Acesso em: 28.set. 2017.

${ }^{42}$ BRASIL. Lei no 6.015 de 31 de Dezembro de 1973. Dispõe sobre os registros públicos, e dá outras providências. Diário Oficial [da] União. Disponível em:http://www.planalto.gov.br/ccivil 03/leis/L6015consolidado.htm. Acesso em: 28.set. 2017.

${ }^{43}$ STURZA, Janaína Machado. SCHORR, Janaína Soares. Transexualidade e os direitos humanos: tutela jurídica ao direito à identidade. Revista Jurídica Cesumar. V. 15, n. 1, p. 265-283. Jan./ Jun. 2015.

${ }^{44}$ BRASIL, op. cit.., 1973.

${ }^{45}$ VIEIRA, op. cit., 2008.

Revista de Direito Brasileira | Florianópolis, SC | v. 22 | n. 9 | p. 77-89 |Jan./Abr. 2019 
autoidentidade sexual é consolidar o princípio constitucional da dignidade da pessoa humana consistindo em promover o desenvolvimento do ser humano em todos os aspectos, garantindo que ele não seja desrespeitado, tampouco violentado em sua integridade psicofísica. A liberdade terá reflexo na seara doméstica, profissional e social do transexual, que terá após longos anos de sofrimentos, constrangimentos, frustrações e dissabores, enfim, uma vida plena e digna. ${ }^{46}$

\section{CONSIDERAÇÕES FINAIS}

O interesse central do texto perpassa questões ligadas à pessoa transexual, bem como ao meio de efetivação do direito da personalidade desses indivíduos, especificamente, por meio da transgenitalização e alteração do nome civil, sob viés sociológico a partir das dimensões da autoidentidade e do corpo na modernidade por meio das contribuições do teórico inglês Anthony Giddens. A abordagem adotada abriu possibilidades para se compreender a construção da autoidentidade e da projeção corporal sob viés sociológico que amplia a discussão sobre a ação social por meio da reflexividade do corpo como aspecto relevante para a construção da autoidentidade dos indivíduos que se constrói na modernidade reflexiva.

Decorre desse processo a formação da autoidentidade que, na sociedade reflexiva, ganha novos contornos, diferentes se pensada na primeira modernidade. Constata-se que, segundo as leituras, o eu não é fixo e, por isso, o corpo também não o é - tem relação com a narrativa biográfica a ser sustentada, ou seja, o corpo é construído reflexivamente pelo indivíduo por meio da adoção de estilos de vida que emergem como elemento essencial para se pensar o agenciamento do corpo na modernidade. Ainda, o agenciamento do corpo não é uma construção livre de riscos, pois, como evidenciado, constrói-se a partir da ação social baseada na multiplicidade de opções e escolhas pulverizadas da/na modernidade.

O corpo e as práticas corporais passam a serem entendidas como um "projeto" por meio do qual os indivíduos buscam a projeção de suas autoidentidades e, a partir disso, o Direito possui papel fundamental na organização desse novo modelo de sociedade criada com base nesse pensamento. Como forma de adequação entre corpo, mente e auoidentidade, o direito tem promovido algumas seguranças no intuito de proteger a dignidade humana do transexual. A cirurgia de mudança de sexo tornou-se um importante instrumento de efetivar esses direitos constitucionais e, de acordo com a evolução jurisprudencial, a justiça tem sido cada vez mais favorável para a concretização desses desejos.

A aparência e a projeção corporal apresentam-se como parte visível da autoidentidade, fazendo com que a personalidade de ser humano construa-se a partir dessa nova roupagem corporal, possibilitando, assim, a formação de diferentes estilos de vidas, derivados da liberdade do indivíduo em reconstruir seu corpo da maneira como almejar (como, por exemplo, a trangenitalização) cabendo ao legislador proporcionar o caminho para a concretização desse novo estilo pessoal, fazendo com que esse mesmo indivíduo esteja sempre inserido no meio social e, tenha protegido sua autoidentidade por meio da aplicação dos princípios que regem a Constituição Federal.

A legislação brasileira tem-se encaminhado para regular a harmonização do corpo com o sexo psicológico do transexual (por meio da transgenitalização e autorização de alteração do nome civil) possibilitando a imersão da autoidentidade do eu na modernidade. A harmonização desses fatores deve, sempre, guardar relação com o princípio da dignidade da pessoa humana, pois, é através dessa relação que os direitos dos transexuais ganharão força e respeito para enfrentar todas as barreiras encontradas no meio cultural.

\footnotetext{
${ }^{46}$ BRASIL. Supremo Tribunal de Justiça. Recurso Especial 1008398/SP - São Paulo. Relatora: Ministra Nancy Andrighi. Pesquisa de Jurisprudência. 〈http://www.stj.jus.br/SCON/jurisprudencia/doc.jsp?livre=Recurso+Especial+1008398\&b=ACOR\&p=true\&l=10\&i =2> . Acesso em: 27.set. 2017.
}

Revista de Direito Brasileira | Florianópolis, SC | v. 22 | n. 9 | p.77-89 |Jan./Abr. 2019 


\section{REFERÊNCIAS}

BRASIL. Constituição da República Federativa do Brasil. Diário Oficial [da] União, Brasília, 5 out. 1988. Disponível em: 〈http://www.planalto.gov.br/ccivil_03/constituicao/constituicao.htm〉. Acesso em: 27.set.2017.

BRASIL. Lei 10.406 de 10 de Janeiro de 2002. Institui o Código Civil. Diária Oficial [da] União. Disponível em: < http://www.planalto.gov.br/ccivil_03/leis/2002/L10406.htm>. Acesso em: 28.set. 2017

BRASIL. Lei no 6.015 de 31 de Dezembro de 1973. Dispõe sobre os registros públicos, e dá outras providências. Diário Oficial [da] União. Disponível em: http://www.planalto.gov.br/ccivil_03/leis/L6015consolidado.htm. Acesso em: 28.set. 2017.

BRASIL. Supremo Tribunal de Justiça. Recurso Especial 1008398/SP - São Paulo. Relatora: Ministra Nancy Andrighi. Pesquisa de Jurisprudência. Disponível em: $<$ http://www.stj.jus.br/SCON/jurisprudencia/doc.jsp?livre=Recurso+Especial+1008398\&b=ACO $\mathrm{R} \& \mathrm{p}=$ true \&l=10\&i=2>. Acesso em: 27.set. 2017.

CARVALHO, Marcelle Saraiva de; HOGEMANN, Edna Raquel. O biodireito de mudar: transexualismo e o direito ao verdadeiro eu. Portal de e-governo, inclusão digital e sociedade do conhecimento. Disponível em: <http://www.egov.ufsc.br/portal/conteudo/o-biodireito-de-mudartransexualismo-e-o-direito-ao-verdadeiro-eu >. Maio, 2012.

DINIZ, Maria Helena. O Estado Atual do Biodireito. $6^{\text {a }}$ ed. Revisada, aumentada e atualizada. São Paulo: Saraiva, 2009. p. 280-281.

FARINA, Roberto. Transexualismo: do homem à mulher normal através dos estados de intersexualidade e das parafilias. São Paulo: Novalunar, 1982, p. 117

FERNANDES, Eric Baracho Dore.Os direitos da personalidade e a problemática dos transexuais. Revista de direito dos monitores da UFF. v.07. Jan/2010.

FERREIRA, Patrícia Fortes Attademo; JARDIM, Lucas Cardoso. a cirurgia de transgenitalização e seus reflexos no direito. Revista Jurídica Cesumar. jul./dez. 2015, v. 15, n. 2, p. 565-580.

GIDDENS, Anthony. As consequências da modernidade. São Paulo: Editora da Universidade Estadual Paulista, 1991.

GIDDENS, Anthony. A transformação da intimidade: sexualidade, amor e erotismo nas sociedades. São Paulo: Editora da Unesp, 1993.

GIDDENS, Anthony. A vida em uma sociedade pós-tradicional. In: BECK, U.; GIDDENS, A.; LASH, S. Modernização reflexiva: política, tradição e estética na ordem social moderna. 1994.

GIDDENS, Anthony. Modernidade e identidade. Rio de Janeiro: Zahar, 2002.

GIDDENS, Anthony. Sociologia. Porto Alegre: Artmed, 2005. 
MARANHÃO, Odon. Curso de Medicina Legal. 4. ed. São Paulo: Revista dos Tribunais, 1989, p 193.

OLIVEIRA, Ana Carolina Gondim de A.; VIANA, Alba Jean Batista; SOUSA, Eduardo Sérgio S. O Corpo intersexual como desconstrução dos gêneros inteligíveis: uma abordagem sóciojurídica. In: Anais... $17^{\circ}$ Encontro Nacional da Rede Feminista Norte e Nordeste de Estudos e Pesquisa sobre a Mulher e Relações de Gênero. Disponível em: http://www.ufpb.br/evento/lti/ocs/index.php/17redor/17redor/paper/view/87>.

RESOLUÇÃO no 2 de 6 de dezembro de 2011. Estabelece estratégias e ações que orientam o Plano Operativo da Política Nacional de Saúde Integral de Lésbicas, Gays, Bissexuais, Travestis e Transexuais, no âmbito do Sistema Único de Saúde (SUS). Disponível em: <http://bvsms.saude.gov.br/bvs/saudelegis/cit/2011/res0002_06_12_2011.html>. Acesso em: 26.set.2017.

SÁNCHES, Alcides Antúnez; SÁNCHES, Amed Ramírez. La auditoría ambiental en el derecho público de Cuba. Revista Direitos Sociais e Políticas Públicas - Unifafibe. V. 4, N. 2, 2016.

SARLET, Ingo Wolfgang. Dignidade da pessoa humana e direitos fundamentais na Constituição Federal de 1988. Porto Alegre: Livraria do Advogado, 2001.

SIQUEIRA, Dirceu Pereira; CASTRO, Lorenna Roberta Barbosa. Minorias e grupos vulneráveis: a questão terminológica como fator preponderante para uma real inclusão social. Revista Direitos Sociais e Políticas Públicas - Unifafibe. V. 5, N. 1, 2017.

SIQUEIRA, Dirceu Pereira; CASTRO, Lorenna Roberta Barbosa. A dimensão cultural do direito fundamental à alimentação. Birigui: Boreal, 2013.

SIQUEIRA, Dirceu Pereira; OLIVEIRA, Flávio Luis (Orgs.). Constitucionalismo, democracia, procedimento e substância. Birigui: Boreal, 2013.

STURZA, Janaína Machado. SCHORR, Janaína Soares. Transexualidade e os direitos humanos: tutela jurídica ao direito à identidade. Revista Jurídica Cesumar. V. 15, n. 1, p. 265-283. Jan./ Jun. 2015.

SZANIAWSKI, Elimar. Limites e possibilidades do direito de redesignação do estado sexual: estudo sobre o transexualismo, aspectos médicos e jurídicos. São Paulo: Revista dos Tribunais, 1999.

SZANIAWSKI, Elimar. Direitos de Personalidade e sua Tutela. 2. ed. São Paulo: Revista dos Tribunais, 2005.

VIEIRA, Tereza Rodrigues. Mudança de sexo: aspectos médicos, psicológicos e jurídicos. São Paulo: Santos, 1996.

VIEIRA, Tereza Rodrigues. Nome e Sexo: Mudanças no Registro Civil. 1. ed. São Paulo: Editora Revista dos Tribunais, 2008. 